\title{
Historical and practical aspects of profitability in commercial beef production systems
}

\author{
A. McRAE \\ Lochalsh Agriculture Ltd, P.O. Box 8013, Palmerston North \\ amcrae@xtra.co.nz
}

\begin{abstract}
The numbers of beef animals in New Zealand have increased markedly since 1960 . In particular the number of animals (especially bulls) reared within the dairy industry for beef production has grown. Early research into aspects of intensive pasture-based beef production systems concentrated on high levels of pasture utilisation and beef production per ha. Farmers have adapted these results and systems and the carcass weight $(\mathrm{CW})$ of bulls slaughtered now at 15-18 months of age have increased and often are over $300 \mathrm{~kg} \mathrm{CW}$. It is shown simplistically that profit/ ha will also increase with increasing $\mathrm{CW}$ and increased efficiency in use of feed within $1 \mathrm{yr}$ bull beef systems. In practice however, utilising more of the pasture dry matter (DM) grown and maintaining pasture quality are important issues. Two year bull systems are shown to be just as profitable as the more technically efficient $1 \mathrm{yr}$ bull system. Where beef production is carried out in conjunction with sheep production, especially on hill country, some commonly used benchmarks of technical and economic efficiency may be misleading with regard to overall system profitability and the contribution of various classes of beef animals.
\end{abstract}

Keywords: beef animals, bulls, economic efficiency, feed efficiency, profitability

\section{Introduction}

Pasture-based intensive beef growing systems are relatively new in New Zealand agriculture. In 1960 there were only about $1 \mathrm{~m}$ cows in the national beef breeding herd (Economic Service 2001/2002), and at that time very few calves born in the national dairy herd were reared for beef production. Improved beef prices through the 1960's and early 1970's led to big increases in the number of beef animals on New Zealand farms. Beef cows numbers peaked at 2.3 million in $1975 / 76$ with the total number of beef cattle at 6.3 million (Economic Service 2001/2002). As the number of beef animals being farmed increased through this period there was also an increase in the amount of trial work investigating aspects of beef production (e.g. Everitt \& Ward 1974). Brougham's work at Aorangi (Brougham et al. 1975) set a production benchmark reporting production of 1000 $\mathrm{kg}$ per ha of net beef carcass production. In addition to the trial work there were also a number of Farm Management studies reported at that time (e.g. Lattimore 1970) that reflected the growing interest in the economics associated with beef production and the comparable returns with dairy and sheep farm systems

The number of beef animals farmed in New Zealand since the peak in 1972/73 has continued to fluctuate in line with the beef schedule price paid to farmers, and the major fluctuations appear to be in the number of calves born in the dairy industry that are reared for beef production.

By the end of the 1970's the author had become involved in the considerable debate betw een scientists, academics, farmers and consultants on the efficiency and economics of beef production. High stocking rates, high levels of pasture utilisation and reported high levels of net carcass production per ha appeared, in the author's opinion, to clash with increasing farmer interest in achieving higher slaughter weights. A commercial scale bull beef unit was established at Tuapaka, Massey University, in 1981 and work at that site and subsequent publications focused on the per ha profit that could be achieved by growing animals faster, resulting in higher slaughter weights and higher trading margins per head (McRae \& Morris 1984; McRae 1985, 1987). Farmer interest in this particular project was intense and large numbers of farmers and farmer groups attended field days at "Tuapaka". The average slaughter weights of Friesan bulls at "Tuapaka" lifted from about $200 \mathrm{~kg}$ carcass weight $(\mathrm{CW})$ to $239 \mathrm{~kg} \mathrm{CW}$ in the early years compared to the average slaughter weights of around $170 \mathrm{~kg} \mathrm{CW}$ reported from Brougham's work. Analysis of what had been achieved at Tuapaka and discussions with farmers at that time led to the conclusion that "bulls finished at $15-20$ months of age need to be nearer $300 \mathrm{~kg} \mathrm{CW}$ than $220 \mathrm{~kg} \mathrm{CW}$ if profit is to be maximised" (McRae 1987).

This conclusion, that $1 \mathrm{yr}$ bulls needed to get to slaughter weights of $300 \mathrm{~kg} \mathrm{CW}$ to maximise profit, was not universally accepted in 1987 . However, in the author's experience many farmers were already well on the way to achieving these slaughter weights at that time and average carcass weights in excess of $300 \mathrm{~kg} \mathrm{CW}$ are now quite commonplace for $15-20$ month Friesan bulls grown on commercial beef 
finishing units. Thus over 30 years the nature of beef production and performance parameters has changed markedly.

This paper sets out to give a current perspective on farm beef production systems and discusses factors that impact on the profitability of those systems.

\section{Basis for comparing systems}

The relative merit of various beef finishing policies for a given expected feed supply can be examined by considering the feed requirements and liveweight gain (LWG) of the growing animals, the number of animals that can utilise the expected feed supply and the likely income and profit to be derived by those animals.

The feed requirements used here are those published by Journeaux et al. (1987) and are based on an analysis of UK energy studies reported in the literature (Minish \& Fox 1982). The resulting feed tables are still used in commercial activity by the author and appear to explain quite well what happens within commercial beef farming systems.

Table 1 describes four theoretical bull beef production systems based on these feed tables. Systems A - C are 1yr bull systems involving Friesan bull calves grown from weaning at 12 weeks of age and $100 \mathrm{~kg}$ liveweight (LW) in November through to slaughter at $15-20$ months of age. These systems then are similar to those reported in the Brougham trials. The actual period of production from weaning through to slaughter is longer than one year for individual animals, and there is a doubling up of stock in late spring when both older and younger replacement animals are on the farm. However the number of replacements coming in and the slaughter animals going out are the same each year so that output and profit from the system can be reported on an annual basis.

System D is a $2 y r$ bull system based on the purchase of light 18 month bulls (380 kg LW) in April which are maintained through the winter before being grown rapidly through spring and early summer and sold from December through February before the replacements come onto the farm.

The 1yr bull systems A, B and C illustrate different levels of average LWG $(A>B>C)$ resulting in CW's of $313 \mathrm{~kg}, 270 \mathrm{~kg}$ and $227 \mathrm{~kg}$ respectively. While the faster growing bulls consume more feed over their lifetime they use feed (pasture dry matter (DM)) more efficiently (shown in Table $1 \mathrm{as} \mathrm{kg} \mathrm{DM} / \mathrm{kg}$ LWG and $\mathrm{kg} \mathrm{DM} / \mathrm{kg} \mathrm{CWG}$ ).

The 2yr bull system, D, illustrates older bulls growing, on average, at about the same rate of LWG as the fastest growing $1 \mathrm{yr}$ bull system. However because these bulls start at a higher LW they use more feed per $\mathrm{kg}$ of LWG.

If it assumed that there are $12000 \mathrm{~kg}$ of pasture $\mathrm{DM} / \mathrm{ha}$ available to be used on an annual basis then, simplistically, the numbers of animals that can be run and the resultant output from each of these systems is as presented in Table 2 .

Table 3 presents the economic outcomes associated with each of these systems for the given assumptions of replacement cost and the price paid per $\mathrm{kg}$ of beef $\mathrm{CW}$ at slaughter.

While the analysis to this point does not address several important practical issues the following preliminary conclusions can be drawn.

- As CW's increase in the $1 \mathrm{yr}$ bull systems so do trading margins per bull and per ha $(\mathrm{A}>\mathrm{B}>\mathrm{C})$

- Young animals that are fed to grow quickly $(\mathrm{A}>\mathrm{B}>\mathrm{C})$ are more efficient than those fed to grow more slowly (as measured by $\mathrm{kg} \mathrm{DM} / \mathrm{kg} \mathrm{LWG).}$ Younger lighter animals are more efficient than older heavier animals grown at about the same average daily gain $(\mathrm{A}>\mathrm{D})$.

- While the decreasing trading margins per bull explain decreasing trading margins/ha for $1 \mathrm{yr}$ bull systems $(A>B>C)$, the lower trading margin per bull in the $2 \mathrm{yr}$ bull system $(\mathrm{D}<\mathrm{A})$ is associated with a similar trading margin/ha $(\mathrm{D}=\mathrm{A})$ as the most profitable 1yr bull system. This result appears to be somewhat irrational in that the same amount of feed used less efficiently would not be expected to generate the same level of profit. However in this case the technical efficiency differences are compensated for by economic efficiencies. That is, the replacements for the $2 \mathrm{yr}$ bull system are purchased at a lower price (per kg LW) and sold at a higher price $(\mathrm{c} / \mathrm{kg} \mathrm{CW})$

However while these conclusions are interesting and explain to some extent why farmers have sought to increase the daily LWG and CW's of animals at slaughter there are a number of practical issues that are not covered in such simplistic analyses.

\section{The practical constraints to profitable bull beef production}

High slaughter weights of young bulls grazed solely on pasture result from high average daily LWG which in turn depends on the grazing animals having access to high pre-grazing allowances and high quality pasture. The move by farmers towards higher slaughter weights in young bulls is justified in economic terms (as shown in Tables $3 a$ and $3 b$ ) but it has two important practical implications.

Firstly, the high daily intakes needed to support high avera ge daily LWG (bulls in system A grow at nearly 

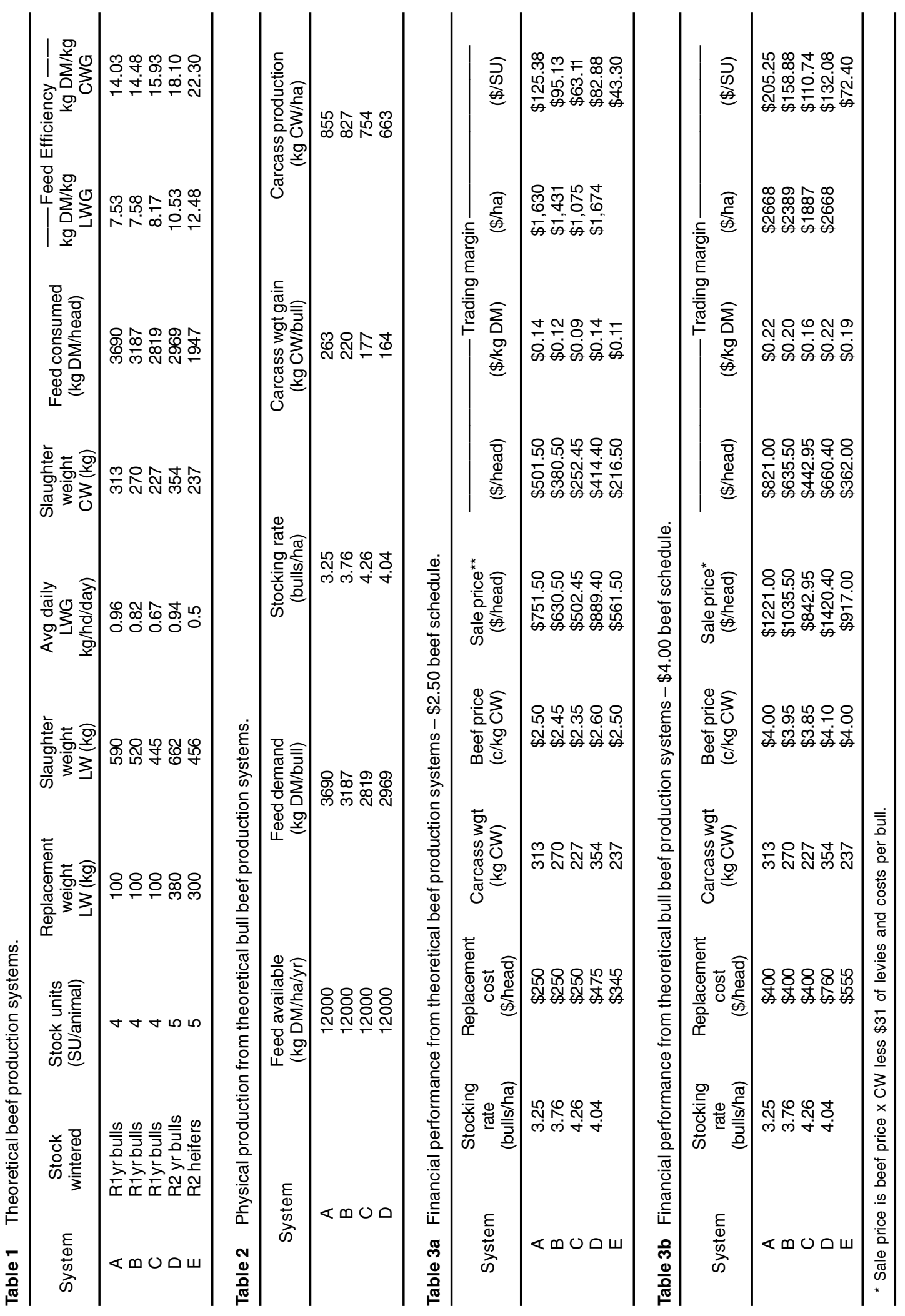

File identification only -289 
$1 \mathrm{~kg} / \mathrm{head} /$ day on average from weaning through to slaughter more than a year later) will result in high post-grazing pasture levels, and these in time will reduce pasture quality and possibly future pasture growth rates, both of which will then impact on future LWG.

Secondly, the (low) stocking rate that allows young bulls to be fully fed during winter will likely not be high enough (even allowing for the same number of replacements to come onto the farm in late spring) to fully utilise spring pasture growth rates.

Addressing both of these issues by running high stocking rates (as in Brougham's work) will increase pasture utilisation and maintain pasture quality, but result in lower average daily liveweight gains and lower trading margins per animal. Furthermore animals grown more slowly on average need to be kept longer to attain any given slaughter weight. The practicality of this in $1 \mathrm{yr}$ bull beef systems is that bulls need to be carried further into summer and that has two quite serious impacts from a profit perspective. In many localities summer pasture growth rates will be less reliable than other times of the year and young animals often do not grow well on summer pastures. However, and importantly from a profit perspective, selling strategies that involve animals being taken further into the summer risk exposure to falling beef schedules caused by the increased supply of animals generally available for slaughter at that time.

These factors have lead many farmers to adopt systems (like D in Tables $1-3$ ) that use older bulls. These bulls do not need to be grown quickly through the winter and accordingly can be stocked at a high rate compared to $1 \mathrm{yr}$ bull systems. In addition these older bulls can be fed supplements as a maintenance diet if necessary in winter and can be made to "cleanup" pastures if necessary. These older animals also appear to have the ability to compensate with intake and LWG when high quality spring pasture is available, and that factor along with the relatively high winter stocking rate allows the older bulls to efficiently utilise high spring pasture growth rates. Finally these bulls reach target slaughter weights before early summer and stock numbers can be reduced readily if dry summer conditions or falling beef schedules are in prospect.

The importance of these factors will vary from farm to farm and throughout climatic zones throughout New Zealand. For example in areas where winter pasture growth rates are very low relative to spring and summer growth rates a $1 \mathrm{yr}$ bull system will be unlikely to support animal LWG that is high enough during winter to reach target slaughter weights: and where winter stocking rates are lowered to assist with higher winter LWG then keeping control of spring pasture will likely become an issue. Soil types and the stage of farm development (fencing, water supply, level of soil fertility and pasture species) will dictate the class of animal most suited to wintering on any one farm. Climate and particularly the reliability of summer pasture growth rates will also have a major bearing on the need to have animals ready for slaughter early in the season, and so dictate to some extent the mix of $1 \mathrm{yr}$ and $2 \mathrm{yr}$ bulls that need to be run.

So while the per head performance described in system $\mathrm{A}$ is now quite commonplace within the commercial bull beef industry, that particular system with the need for high average daily LWG and reduced pasture utilisation as a result, is unlikely to consistently achieve in practice the per ha margins shown in Table 3.

The very clear farmer response to this conundrum has been to design farm systems that allow higher average daily liveweight gains, higher slaughter weights and higher margins per head while using other strategies to handle the feed utilisation and feed quality issues referred to above. There are plenty of commercial farm examples of bull beef systems where

- A mix of $1 \mathrm{yr}$ and $2 \mathrm{yr}$ bull are run in conjunction to give flexibility in how the bulls are fed over winter, to enable the control of spring pasture growth rates and to have animals ready for sale early in the season if climate or market conditions make that advisable.

- A low winter stocking rate that allows $1 \mathrm{yr}$ bulls to achieve high average daily LWG is combined with the purchase of extra cattle in the late winter.

- A low winter stocking rate that allows $1 \mathrm{yr}$ bulls to achieve high average daily LWG is combined with a spring cropping programme where the area taken out for cropping effectively lifts the spring stocking rate of cattle to a point where pasture utilisation remains high.

- Intensive beef systems are combined with breeding stock systems, the use of $\mathrm{N}$, and making and using hay and silage.

The mix of these strategies that are employed and the economic returns associated with them will vary from farm to farm and between years as the ratio of replacement price, sale price and beef prospects vary due to overseas markets and currency fluctuations. On-farm strategies will also change due to local supply and demand of cattle which are influenced mainly by climatic events in different parts of the country and various farmers' perceptions of the current and future risk around likely returns. 
It is the authors's experience that beef finishing systems are ever changing, due in part to the fact that they can be readily changed in response to markets and the availability of stock. This has resulted in there now being few if any stand-alone $1 \mathrm{yr}$ bull beef systems that rely entirely on purchase of $100 \mathrm{~kg}$ weaner bulls and selling $15-18$ month bulls.

\section{Other beef systems}

This paper has concentrated on bull beef production because over the three decades of change within the beef industry the numbers of bulls reared and grown has been the major change that has occurred, and because for almost all of that time bull beef production has been more profitable than steer or heifer based beef systems.

However there are very few New Zealand farms that are entirely devoted to beef production. Geographically beef numbers make up a greater part of farm systems in the north of New Zealand with considerably fewer cattle being run in the south (eg. Economic Service 2001/2002). Most beef cattle are run in conjunction with some other stock classes. In these situations the factors impacting on the profitability of beef production can be quite different to those discussed above and are a good deal more complex and difficult to explain.

The role of the beef breeding cow in complementing sheep production within hill country farming systems has been the subject of many articles in recent times (e.g. Beef Council 2002). The real issue in many of these discussions centres around putting a value on feed that cannot be used by sheep (especially where the sheep are fed to achieve high performance) but is quite acceptable as a maintenance diet for beef breeding cows.

Where hill country breeding farms have been fully developed with fencing, fertiliser, water supply and access, the complementary grazing by beef animals that is required can often be achieved with young growing cattle rather than breeding cows. The question then becomes what class and type of cattle should be used.

The changes in the beef industry over the past 30 years have resulted in Friesan bulls now being run as the cattle component in hill country sheep and beef systems. This is not surprising given the ready availability of Friesan bulls from the dairy industry and the apparent profitability of bull beef as discussed earlier in this paper.

Some farmers however do have real concerns about the suitability of bulls within their farming systems from both a behavioural and economic standpoint.

The complexity of these economic issues can be illustrated by comparing the likely returns from bulls and, for example, a heifer beef system defined as system $E$ in Tables 1, 3a and $3 b$. These heifers are bred from a beef cow herd and identified as not required for replacements and sold as empty heifers at 18 months of age. As the cattle component of a hill country sheep breeding farm they could be grown slowly from $300 \mathrm{~kg} \mathrm{LW}$ in summer, held at about maintenance through autumn and winter cleaning up poor quality feed surplus to sheep requirements and then grown rapidly (at about $1 \mathrm{~kg} /$ head/day LWG) as feed surplus to sheep requirements becomes available in spring. They would be slaughtered in early summer at $456 \mathrm{~kg} \mathrm{LW}, 237 \mathrm{~kg} \mathrm{CW}$, before replacements were purchased in mid summer.

Now these heifers could be compared with the bull system B (1yr bull system, $270 \mathrm{~kg} \mathrm{CW}$ bull at 18 months of age) as an alternative beef component in a high performance hill country sheep breeding system. In the author's experience these heifers are becoming an increasingly popular class of animal for this job. The reason for this growth in popularity is not immediately obvious from many of the benchmarks commonly used to compare alternative components within a pastoral farming system.

Table 1, system E shows the heifers wintering more SU's per head than the $1 \mathrm{yr}$ bull system $\mathrm{B}$, achieving considerably lower average daily LWG (heifers at 0.50 $\mathrm{kg} \mathrm{LWG} /$ head/day, bulls at $0.82 \mathrm{~kg} \mathrm{LWG} /$ head/day) at much lower feed efficiency levels (heifers at 12.48 $\mathrm{kg} \mathrm{DM} / \mathrm{kg}$ LWG and bulls at $7.58 \mathrm{~kg} \mathrm{DM} / \mathrm{kg}$ LWG )

Tables $3 \mathrm{a}$ and $3 \mathrm{~b}$ also show that by most economic indicators the bull system (B) far outperforms the heifers. At a $\$ 2.50$ beef schedule (Table 3a) the trading margin for the heifers is not much more than half of that for the bulls ( $\$ 216.50$ vs $\$ 380.50)$ and the return per SU wintered is less than half that from the bulls (\$43.30 vs $\$ 95.13)$.

However when compared on a feed consumed basis the heifers generate nearly the same returns as the bulls (heifers at $11 \mathrm{c} / \mathrm{kg} \mathrm{DM}$ and bulls at $12 \mathrm{c} / \mathrm{kg}$ $\mathrm{DM}$ at a $\$ 2.50$ beef schedule, and $19 \mathrm{c}$ and $20 \mathrm{c} / \mathrm{kg}$ DM respectively at a $\$ 4$ beef schedule).

To achieve the high average daily LWG defined in system B the bulls will have to use quality feed for most of the year and especially through the autumn and winter period. The heifers in system $\mathrm{E}$ can achieve the slaughter weights defined by being fed at maintenance on low quality feed during autumn and winter. If the heifers are using poor quality feed that is surplus to the ewes requirements and the bulls are competing with the sheep component for high quality feed then the true economic return from the bulls can only be compared to the heifers if the loss in sheep 
production and income is accounted for. Conversely if bulls within a hill country sheep and beef system are fed on poor quality feed through autumn and winter and as a result achieve lower average daily LWG and CW then they will earn less on per $\mathrm{kg}$ of $\mathrm{DM}$ basis. The $1 \mathrm{yr}$ bull system $\mathrm{C}$, for example, earns only $9 \mathrm{c} / \mathrm{kg} \mathrm{DM}$ at a $\$ 2.50$ beef schedule and $16 \mathrm{c} / \mathrm{kg}$ $\mathrm{DM}$ at a $\$ 4$ beef schedule while the heifer policy $\mathrm{E}$ would earn $11 \mathrm{c} / \mathrm{kg} \mathrm{DM}$ and $19 \mathrm{c} / \mathrm{kg}$ DM respectively for those two beef price situations.

\section{Conclusion}

Beef production systems in New Zealand have changed quite dramatically in the last thirty years. The move by farmers to feed beef animals to achieve higher average LWG and so reach higher $\mathrm{CW}$ at slaughter is consistent with achieving higher profits/ ha. On some farms and in some situations the feed demands of these rapidly growing animals may not fit particularly well with the pattern of feed supply from pasture and may also result in lower levels of pasture production and utilisation than was reported in earlier farmlet studies by Brougham (Cosgrove et al. 2003). Farmers have devised a number of ways to run animals achieving high slaughter weights and still maintain pasture quality and high utilisation. This will often involve different ages and classes of beef animals being run on the same property, combining beef production within a cropping regime, making and feeding supplementary feed, or running older animals and compromising total beef output per ha to secure higher profits/ha.

Where beef animals are run in conjunction with other stock, and sheep in particular on hill country, then the quality and timing of feed available may make some classes of beef stock quite profitable in an overall system sense, when those same stock compared with other beef options on a stand alone basis do not appear to be particularly profitable.

Farmers have been and will always be driven by the profit that they can derive from their given land resource. Technical efficiency measures like beef production/ha are not particularly helpful in defining profitability or in establishing ways to increase profitability for an y particular property. This later task will generally require a more detailed analysis and consideration of the feed likely to be available from pasture along with the feed requirements, expected performance and expected returns from the beef animals that may be able to utilise that feed.

\section{ACKNOWLEDGEMENTS}

The author wishes to thank NZGA and their editorial staff for the opportunity to express the opinions contained here and for the assistance and tolerance involved in the preparation of this paper. The contribution of those who commented on an earlier draft is also appreciated. Many of the Massey University staff involved with the Tuapaka project were important contributors to the authors understanding of farming systems. Most importantly the author would like to gratefully acknowledge the contribution made by farmers in this and related subject areas, during the Tuapaka project and subsequently. Farmers in general have always inspired the author with their ability and preparedness to observe, analyse, adapt and experiment, usually in circumstances when they know that they will suffer direct economic loss if they get it wrong. In the authors opinion their knowledge and experience remains undervalued within New Zealand agriculture.

\section{REFERENCES}

Beef Council. 2002. Field Day Proceedings. Northland Beef Council. Whangarei.

Brougham, R.W.; Causley, D.C.; Madgwick, L.E. 1975. Pasture management systems and animal production. Proceedings of the Ruakura Farmers Conference 27: 65-69.

Cosgrove, G.P.; Clark, D.A.; Lambert, M.G. 2003. High production dairy-beef grazing systems: a review of research in the Manawatu. Proceedings of the New Zealand Grassland Association 65:

Economic Service. 2001/02 Annual Review of the New Zealand Sheep and Beef Industry. Publication No. 2227.

Everitt, G.C., Ward, J.D. 1974. Bull Beef Production. Proceedings of the Ruakura Farmers Conference 26: 81-96.

Journeaux, P.R.; McRae, A.F.; Parker, W.J. 1987. Bull beef production on hill country. Proceedings of New Zealand Society of Animal Production 47:119-122.

Lattimore, R.G. 1970. The comparative profitability of milk and beef production on seasonal supply dairy farms. M AgriSc Thesis, Massey University, Palmerston North.

McRae, A. F.; Morris, S. T. 1984. Profitable bull beef systems. Publication No. 1 Tuapaka Farm Series. Massey University, Palmerston North.

McRae, A. F. 1985. Tuapaka bull beef unit - the first two seasons. Publication No. 2. Tuapaka Farm Series. Massey University, Palmerston North.

McRae, A. F. 1987. Tuapaka bull beef unit - seasons three and four. Publication No. 4. Tuapaka Farm Series. Massey University, Palmerston North.

Minish, G.I.; Fox, D.G. 1982. pp 177-244. In: Beef Production and Management. $2^{\text {nd }}$ Edition. Reston Publishing Co, Reston. 